\title{
ARTICLE \\ Optimization of the extraction of natural phenolic antioxidants from the seeds of Tamarindus indica $L$. - an undervalued by product of food processing - using response surface methodology
}

\author{
Atreyi Sarkar, Uma Ghosh* \\ Department of Food Technology and Biochemical Engineering, Jadavpur University, Jadavpur, Kolkata - 700032, \\ India
}

\begin{abstract}
The seeds of Tamarindus indica are known to possess a wide range of phenolic compounds with high antioxidant activity as measured by the ferric reducing antioxidant power (FRAP). In the present study, the optimum conditions for the extraction of crude phenolic antioxidants from Tamarind seed were determined using response surface methodology (RSM). A central composite design (CCD) was used to investigate the effects of four independent variables, namely concentration of extractable solids in solvent $\left(\mathrm{g} / \mathrm{ml} ; X_{1}\right)$, extraction time $\left(\mathrm{h} ; X_{2}\right)$, extraction temperature $\left({ }^{\circ} \mathrm{C} ; X_{3}\right)$ and solvent concentration $\left(\%, v / v ; X_{4}\right)$ on the responses of total polyphenol content (TPC) and FRAP. The CCD consisted of 30 experimental runs. A second-order polynomial model was used for predicting the responses. Canonical analysis of the surface responses revealed that the predicted optimal conditions for the maximal yield of TPC and FRAP were concentration of extractable solids in solvent of $0.049 \mathrm{~g} / \mathrm{ml}$, extraction time of $3.24 \mathrm{~h}$, extraction temperature of $45^{\circ} \mathrm{C}$ and a solvent concentration of $50 \%$. The experimental values in the optimised condition coincided with the predicted ones within a 95\% confidence interval, hence indicating the suitability of the model and the success of RSM in optimizing the extraction parameters.
\end{abstract}

\section{KEY WORDS}

central composite design

flavonoid

mass transfer

natural antioxidant optimization

solvent extraction

\section{ARTICLE INFORMATION}

Submitted

19 January 2018

Accepted

19 May 2018

*Corresponding author

E-mail: ughoshftbe@yahoo.co.in

\section{Introduction}

Nature and its diversity have distributed the sources of natural antioxidants in different edible and nonedible parts of the plants. Tamarind pulp is regarded as a popular and well-known condiment in different cuisines across the globe, but the seed of this pulpy fruit is considered a waste item. The seeds of tamarind fruit provide a wide spectrum of natural antioxidants, which principally occur as polyphenols. Polyphenolic compounds namely, 2-hydroxy-3',4'-dihydroxyacetophenone, methyl 3,4-dihydroxybenzoate, 3,4-dihydroxyphenyl acetate, (-)-epicatechin (Tsuda et al. 1995) and procyanidins (Sudjaroen et al. 2005) have been isolated from the seeds. These have therapeutic potential in ameliorating ailments resulting from oxidative stress in human as well as augmenting the nutritive value when added to any food by commuting it into a functional food.

However, the newly emerging need for food safety and food sustainability has built up the concern of food researchers on recovering natural ingredients for application in food. Hence, it is of immense importance to extract natural antioxidants in the active form they are originally present in the source. Extensive studies (Turkmen et al. 2006; Akowuah et al. 2005; Yilmaz and Toledo 2006; Yu et al. 2005) addressing this concern are being executed and the reports generated suggest that effects of individual process parameters along with their composite effects influence the process and efficacy of extraction. Solvent extraction being the most utilised unit operation for mass transfer has been selected here to extract polyphenols from tamarind seed. The first step in solvent extraction is the sorption of the solvent by the solid matrix and consequent swelling up. This operation is followed by diffusion and solubilisation of the extractives into the solvent. The polarity and composition of the solvent medium influence the diffusivity of the solute, hence affects the efficacy of extraction (Treybal 1981). Several other factors such as extraction time, temperature, concentration of extractable solids in solvent and the composition of the solvent influence the process of solvent extraction from milled plant material (Spigno et al. 2007; Pinelo et al. 2005; Cacace and Mazza 2003). The state of the art technologies for recovery of antioxidants from natural sources aim at optimising the influence of 
process parameters in order, to maximise the extraction of antioxidants.

Classical optimization studies use the one-factorat-a-time (OFAT) approach, in which only one factor is a variable at a time while all others are kept constant. Though conventional, this approach is expensive in terms of cost and time resulting in an undesirable cost to benefit ratio. Further, it ignores possible interaction effects between variables and hence the Response Surface Methodology (RSM) comes into play to overcome these difficulties. RSM is a statistical tool for mathematical modelling with the aim to study the individual and interaction effects of several independent variables by varying them simultaneously in designed, limited number of experiments. Central composite design (CCD) needs a bare number of experiments to be performed. This model is composed of a core full factorial, that forms a cube $( \pm 1)$ which determines the main and interaction effects and axial points $( \pm \alpha)$ which evaluate the main and quadratic effect. The value of $\alpha$ is calculated as $1 / 4^{\text {th }}$ power to the number of factorial runs. The axial points being outside of the design space confers rotatability to the model (Anderson and Whitcomb 2016).

In view of the above facts, the present study aimed at applying a central composite experimental design by RSM for maximizing the phenolic antioxidant extraction from tamarind seed by means of optimising the effects of four independent variables (extractable solid in solvent, extraction time, extraction temperature and solvent concentration) and their interactions on total antioxidant activity measured by FRAP and total polyphenol content. Finally the work aimed to verify the validity of the proposed model by conducting batch experiments in the experimental range as predicted.

\section{Materials and Methods}

\section{Materials}

Tamarind seeds were purchased from a local market of Jadavpur. Two kg of raw seeds were procured at once to maintain the uniformity in the composition and characteristic properties of the sample throughout the study. The seeds were frozen at $-20{ }^{\circ} \mathrm{C}$ until further study. Sodium carbonate, ferric chloride hexahydrate, iron(II)sulfate-heptahydrate, acetic acid, sodium acetate, hexane, hydrochloric acid and Folin-Ciocalteu's reagent were supplied by Merck (Germany). Other chemicals used for experimental purposes were gallic acid (SDFCL, Mumbai, India) and 2,4,6-Tri(2-pyridyl)-s-triazine (HiMedia, Mumbai, India).

\section{Preparation of sample}

The seeds were cleaned under running tap water then rinsed with bi-distilled water followed by regular grading and sorting procedures. To remove the superficial moisture, sun drying was done for 4 consecutive days and 7 hours daily by exposing the seeds to direct sunlight at an average atmospheric temperature of $39^{\circ} \mathrm{C}$. Finally, the seeds were dried in a hot air oven (DTC 72S1, International Commercial Traders, Kolkata, India) at $60{ }^{\circ} \mathrm{C}$ to attain a constant moisture content of $9 \%$. Dried seeds were disintegrated by crusher grinder (Denver Lab) and were sieved through IS standard ASTM standars sieves to obtain an average sized particle of $0.25 \mathrm{~mm}$. This particle size was found to be effective for extraction by previous studies (Herodež et al. 2003; Laroze et al. 2010). The obtained samples were packaged in dark coloured airtight vacuum saver glass container and stored in dark at $25^{\circ} \mathrm{C}$ for further use.

\section{Selection of appropriate extraction conditions}

The foremost step of the preliminary experiment was to select an appropriate extraction medium and its corresponding extraction technique for the extraction of phenolics from the sample.

\section{Selection of suitable extraction medium}

Previous work (Sarkar and Ghosh 2016) pointed towards better capacity of a binary solvent system than a single solvent extraction medium. Moreover, due to the dehydrating and coagulant effect of absolute alcohol, in the present study aqueous alcohol was selected for solvent extraction. Based on these, three different solvent systems, namely boiling water, $50 \%$ ethanol and 50\% methanol were tested.

For boiling water extraction, $2 \mathrm{~g}$ of sample was put in a muslin cloth sac (Nakchat et al. 2014) and sealed properly. It was immersed in $50 \mathrm{ml}$ of boiling water and held in shaking condition to allow the leaching out of the solute. The red-brown extract was filtered through a Büchner funnel using Whatman filter paper (no 4.1). The filtrate was collected in borosilicate test tube with screw cap and marked as WE (boiling water extract).

A single stage batch processing technique was used for the extraction of sample in two different batches using $50 \%(\mathrm{v} / \mathrm{v})$ ethanol and $50 \%(\mathrm{v} / \mathrm{v})$ ethanol as solvents. In a temperature controlled $\left(25 \pm 1{ }^{\circ} \mathrm{C}\right)$ water bath shaker (Sicco, Kolkata, India) a constant shaking speed of $60 \mathrm{rpm}$ was set up. Two g of solid sample was extracted in $50 \mathrm{ml}$ of each solvent system and the extracts were collected in borosilicate test tubes with screw cap and marked as EE and $\mathrm{ME}$ for aqueous ethanolic and methanolic extracts, respectively. 
Table 1. Experimental range of coded and actual values for central composite design (CCD).

\begin{tabular}{llllll}
\hline Independent variables & \multicolumn{5}{c}{ Coded levels } \\
\cline { 2 - 6 } & $-\mathrm{a}$ & -1 & 0 & 1 & $+\mathrm{a}$ \\
\hline Concentration of extractable solids in solvent $\left(\mathrm{g} / \mathrm{ml}, \mathrm{X}_{1}\right)$ & 0.03 & 0.04 & 0.05 & 0.06 & 0.07 \\
Extraction time $\left(\mathrm{h} ; \mathrm{X}_{2}\right)$ & 2 & 2.5 & 3 & 3.5 & 4 \\
Extraction temperature $\left({ }^{\circ} \mathrm{C} ; \mathrm{X}_{3}\right)$ & 30 & 35 & 40 & 45 & 50 \\
Solvent concentration $\left(\%, \mathrm{v}: \mathrm{v} ; \mathrm{X}_{4}\right)$ & 40 & 45 & 50 & 55 & 60 \\
\hline
\end{tabular}

The extracts obtained from various experimental runs were defatted with hexane in a separating funnel and filtered as described in the previous work by the authors (Sarkar and Ghosh 2016). The freshly prepared extracts were examined for TPC and antioxidant activity by FRAP to determine the best solvent medium.

\section{Selection of experimental ranges of the independent vari- ables}

The second step of the preliminary study was to set the ranges of experimental variables namely extractable solid in solvent $(\mathrm{g} / \mathrm{ml})$, extraction time $(\mathrm{h})$, extraction temperature $\left({ }^{\circ} \mathrm{C}\right)$ and solvent concentration $(\%, v / v)$ for further optimisation studies utilising RSM. Classical single factor optimisation (OFAT) experiments had been performed by the authors previously (Sarkar and Ghosh 2016); in the present study, the optimised values of design variables by OFAT were used as central points for experimental design of RSM. The five levels of the coded design variables are indicated in Table 1.

\section{Experimental design for the response surface procedure}

The RSM used a four numeric factor, five level and rotatable central composite design (CCD) consisting of 30 experimental runs with 6 centre points. The different levels of the variables as described in Table 1 were used to generate the CCD design matrix. The response surface regression was analysed by Design Expert Software V.8.0.6 (Stat-Ease, Minneapolis, USA). Experimental data were fitted to a second-order polynomial as follows:

$$
\begin{aligned}
Y= & \beta_{0}+\beta_{1} X_{1}+\beta_{2} X_{2}+\beta_{3} X_{3}+\beta_{4} X_{4}+\beta_{12} X_{1} X_{2}+\beta_{13} X_{1} X_{3} \\
& +\beta_{14} X_{1} X_{4}+\beta_{23} X_{2} X_{3}+\beta_{24} X_{2} X_{4}+\beta_{34} X_{3} X_{4}+\beta_{11} X_{1}^{2}+ \\
& \beta_{22} X_{2}^{2}+\beta_{33} X_{3}^{2}+\beta_{44} X_{4}^{2}
\end{aligned}
$$

Where $Y$ is the predicted response, $\beta_{1}, \beta_{2}, \beta_{3}, \beta_{4}$ are the coefficients for the linear terms, $\beta_{11}, \beta_{22}, \beta_{33}, \beta_{44}$ are the coefficients for the quadratic and $\beta_{12}, \beta_{13}, \beta_{14}, \beta_{23}, \beta_{24}, \beta_{34}$ are the coefficients for interaction terms respectively. $X$ represents the coded values for the independent process variables.

\section{Determination of the optimum conditions and valida- tion of the model}

Optimum desirability of the response variables, i.e. the maximum yield for total antioxidant activity based on the values of TPC and FRAP were predicted by the model to determine the region of response surface where it should reach its optimum value. The validity and adequacy of the predictive extraction model was verified by performing three experimental replicates at the predicted optimized conditions and the experimental and predicted values were compared.

\section{Analyses of the response variables}

\section{Determination of total polyphenolic content (TPC)}

TPC of the extracts were determined by the method described by Malik and Singh (1980) with some changes. Briefly, $0.75 \mathrm{ml}$ of different concentrations of the extracts were taken, to which $3 \mathrm{ml}$ of distilled water and $0.5 \mathrm{ml}$ of Folin-Ciocalteu reagent (diluted to 1:1 with water) and $1 \mathrm{ml}$ of $20 \% \mathrm{Na}_{2} \mathrm{CO}_{3}$ were added. The absorbance was read after 2 hours of incubation by spectrophotometer (Hitachi U-2000) at $760 \mathrm{~nm}$ wavelength and plotted in a standard calibration curve of gallic acid. These results are expressed as milligram gallic acid equivalents per gram of dry sample (mg GAE/g).

\section{Determination of total antioxidant activity (FRAP assay)}

The FRAP assay was carried out according to the method of Benzie \& Strain (1996) with minor modifications. Briefly, sodium acetate buffer ( $300 \mathrm{mM}, \mathrm{pH} 3.6), 10 \mathrm{mM}$ TPTZ solution (dissolved in $40 \mathrm{mM} \mathrm{HCl}$ ) and $20 \mathrm{mM}$ iron(III) chloride solution were mixed in a ratio $(\mathrm{v} / \mathrm{v})$ of 10:1:1, respectively, to prepare the FRAP reagent. The freshly prepared reagent was warmed to $37^{\circ} \mathrm{C}$ in a water bath before use and $3 \mathrm{ml}$ of this was added to $100 \mu \mathrm{l}$ of the sample solution. The absorbance was measured at $593 \mathrm{~nm}$ after $4 \mathrm{~min}$ and plotted in a standard calibration 
curve of $\mathrm{FeSO}_{4}$ solution. The results are expressed as $\mu \mathrm{mol}$ $\mathrm{Fe}(\mathrm{II}) / \mathrm{g}$ dry sample.

\section{Statistical analysis}

Results of the analyses are expressed as mean \pm standard deviation of triplicate assays and analysed by Microsoft Excel 2007. Correlations between variables are established by Pearson correlation values using Minitab Statistical Software (Version 17).

\section{Results and Discussions}

\section{Selection of suitable extraction medium}

Antioxidant extract of the sample by methanol (ME) was found to have the highest FRAP and TPC values
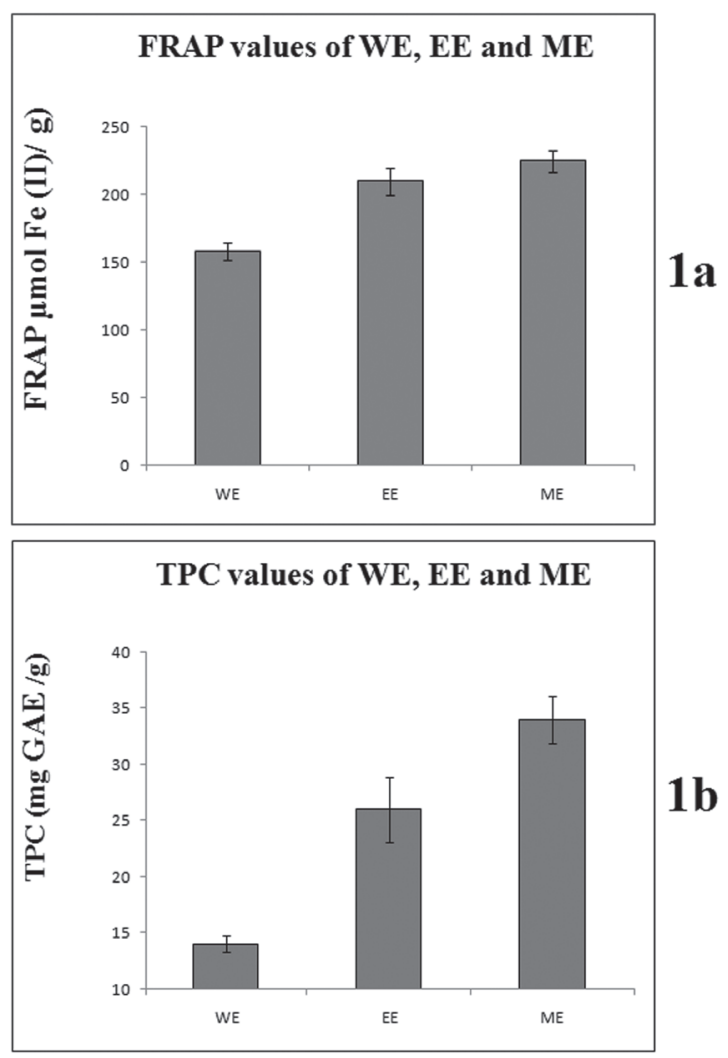

Figure 1. Ferric reducing antioxidant power (FRAP) (1a) and total polyphenol content (TPC) (1b) of boiling water extract (WE), ethanolic extract (EE) and methanolic extract (ME) of tamarind seed.

followed by ethanol (EE) and aqueous extract (WE) (Figs. 1a, b). There was comprehensible, but no significant $(\mathrm{p}<0.05)$ difference in TPC and FRAP values between the methanol (ME) and ethanol extracts (EE), but a signifi-
Table 2. CCD design with experimental responses.

\begin{tabular}{|c|c|c|c|c|c|c|c|}
\hline \multicolumn{2}{|c|}{ Run } & \multicolumn{4}{|c|}{ Independent variables ${ }^{a}$} & \multicolumn{2}{|c|}{ Responses $^{a}$} \\
\hline Std. order & Run no. & $\overline{X_{1}}$ & $\mathrm{X}_{2}$ & $x_{3}$ & $\mathrm{X}_{4}$ & $\overline{Y_{1}}$ & $Y_{2}$ \\
\hline 13 & 1 & 0.04 & 2.5 & 45 & 55 & 201 & 28.34 \\
\hline 24 & 2 & 0.05 & 3 & 40 & 60 & 200 & 32.44 \\
\hline 8 & 3 & 0.06 & 3.5 & 45 & 45 & 199.05 & 32 \\
\hline 20 & 4 & 0.05 & 4 & 40 & 50 & 181.89 & 35.33 \\
\hline 5 & 5 & 0.04 & 2.5 & 45 & 45 & 200.03 & 28 \\
\hline 6 & 6 & 0.06 & 2.5 & 45 & 45 & 197.34 & 29 \\
\hline 3 & 7 & 0.04 & 3.5 & 35 & 45 & 192 & 32.98 \\
\hline 12 & 8 & 0.06 & 3.5 & 35 & 55 & 184 & 29 \\
\hline 22 & 9 & 0.05 & 3 & 50 & 50 & 212.78 & 35.87 \\
\hline 4 & 10 & 0.06 & 3.5 & 35 & 45 & 189.45 & 28.79 \\
\hline 16 & 11 & 0.06 & 3.5 & 45 & 55 & 191.54 & 32 \\
\hline 30 & 12 & 0.05 & 3 & 40 & 50 & 227.72 & 32.87 \\
\hline 23 & 13 & 0.05 & 3 & 40 & 40 & 202 & 32 \\
\hline 25 & 14 & 0.05 & 3 & 40 & 50 & 225.54 & 32.56 \\
\hline 26 & 15 & 0.05 & 3 & 40 & 50 & 227.15 & 32.53 \\
\hline 18 & 16 & 0.07 & 3 & 40 & 50 & 179.98 & 20 \\
\hline 28 & 17 & 0.05 & 3 & 40 & 50 & 227 & 32.65 \\
\hline 17 & 18 & 0.03 & 3 & 40 & 50 & 194 & 22.54 \\
\hline 7 & 19 & 0.04 & 3.5 & 45 & 45 & 200.42 & 30 \\
\hline 1 & 20 & 0.04 & 2.5 & 35 & 45 & 200.67 & 30 \\
\hline 19 & 21 & 0.05 & 2 & 40 & 50 & 191 & 30.12 \\
\hline 11 & 22 & 0.04 & 3.5 & 35 & 55 & 193.87 & 33 \\
\hline 9 & 23 & 0.04 & 2.5 & 35 & 55 & 198 & 30.65 \\
\hline 27 & 24 & 0.05 & 3 & 40 & 50 & 227.12 & 32 \\
\hline 15 & 25 & 0.04 & 3.5 & 45 & 55 & 203 & 31.94 \\
\hline 29 & 26 & 0.05 & 3 & 40 & 50 & 227.65 & 32.65 \\
\hline 10 & 27 & 0.06 & 2.5 & 35 & 55 & 191.87 & 26 \\
\hline 2 & 28 & 0.06 & 2.5 & 35 & 45 & 199 & 26 \\
\hline 21 & 29 & 0.05 & 3 & 30 & 50 & 206.65 & 32.56 \\
\hline 14 & 30 & 0.06 & 2.5 & 45 & 55 & 192.55 & 29 \\
\hline
\end{tabular}

${ }^{a}$ Experiments were run in triplicate.

$\mathrm{X}_{1}=$ concentration of extractable solids in solvent $(\mathrm{m}: \mathrm{v}, \mathrm{g} / \mathrm{ml}) ; \mathrm{X}_{2}=$ extraction time (h); $X_{3}=$ extraction temperature $\left({ }^{\circ} \mathrm{C}\right)$, and $\mathrm{X}_{4}=$ solvent concentration $(\%, v: v) . Y_{1}=$ FRAP, and $Y_{2}=$ TPC.

cant difference was observed between aqueous (WE) and alcoholic extracts (ME and EE). A strong correlation of 0.98 between FRAP and TPC values of different extracts indicated that the antioxidant activity of the sample may owe to the polyphenols present in the sample. However, an extracting solvent in food system is selected not only for the purpose of acquiring maximum extractives, but health hazard and safety are also considered.

The toxicity of methanol is well-known (McMartin et al. 1980; Clay et al. 1975) in contrast to ethanol which has "Generally Recognized as Safe" (GRAS) status.

The discrepancy in antioxidant activity between extracts from different solvent can be addressed to the different diffusivity, solubility and partition coefficient. Many investigations (Valgimigli et al. 1996; MacFaul et al. 1996) have reported hydrogen bonding and electron donor-acceptor interaction between the solute and solvent as the reason of variation in antioxidant activities of dif- 


\section{Optimisation of the extraction parameters}

ferent extracts. Greater FRAP and TPC values of alcoholic extracts (ME and EE) may be ascribed to the less polarity of the alcohol solution which makes it more efficient than water to break the cell wall structure and leach out the soluble antioxidants in the solution. Hence, in this study ethanol in different dilutions with water was chosen as medium for phenolic extraction from tamarind seed.

Table 3. Analysis of variance (ANOVA) for the quadratic polynomial model.

\begin{tabular}{|c|c|c|c|c|c|}
\hline Source & $\begin{array}{l}\text { Sum of } \\
\text { squares }\end{array}$ & $\mathrm{DF}^{\mathrm{a}}$ & $\begin{array}{l}\text { Mean } \\
\text { square }\end{array}$ & F-value & $\begin{array}{l}\text { P-value } \\
\text { Prob }>F\end{array}$ \\
\hline \multicolumn{6}{|l|}{ FRAP $^{b}$} \\
\hline Model & 5968.866 & 14 & 426.3475 & 275.013 & $<0.0001 * *$ \\
\hline$X_{1}$ & 217.3822 & 1 & 217.3822 & 140.2211 & $<0.0001 * *$ \\
\hline$X_{2}$ & 85.6926 & 1 & 85.6926 & 55.27551 & $<0.0001 * *$ \\
\hline$x_{3}$ & 97.32454 & 1 & 97.32454 & 62.77862 & $<0.0001 * *$ \\
\hline$X_{4}$ & 28.44904 & 1 & 28.44904 & 18.35088 & $0.0007 *$ \\
\hline$x_{1} x_{2}$ & 2.488506 & 1 & 2.488506 & 1.605196 & 0.2245 \\
\hline$x_{1} x_{3}$ & 0.878906 & 1 & 0.878906 & 0.566933 & 0.4631 \\
\hline$X_{1} X_{4}$ & 47.71356 & 1 & 47.71356 & 30.77735 & $<0.0001$ ** \\
\hline$x_{2} x_{3}$ & 69.34726 & 1 & 69.34726 & 44.73204 & $<0.0001 * *$ \\
\hline$x_{2} x_{4}$ & 1.632006 & 1 & 1.632006 & 1.052716 & 0.3211 \\
\hline$x_{3} x_{4}$ & 1.339806 & 1 & 1.339806 & 0.864234 & 0.3673 \\
\hline$X_{1}^{2}$ & 2764.442 & 1 & 2764.442 & 1783.187 & $<0.0001$ ** \\
\hline$X_{2}^{2}$ & 2839.988 & 1 & 2839.988 & 1831.917 & $<0.0001 * *$ \\
\hline$X_{3}^{2}$ & 520.9329 & 1 & 520.9329 & 336.0247 & $<0.0001$ ** \\
\hline$X_{4}^{2}$ & 1172.006 & 1 & 1172.006 & 755.9953 & $<0.0001 * *$ \\
\hline Residual & 23.25423 & 15 & 1.550282 & & \\
\hline Lack of fit & 20.15023 & 10 & 2.015023 & 3.245848 & $0.1029^{N S}$ \\
\hline Pure error & 3.104 & 5 & 0.6208 & & \\
\hline Cor total & 5992.12 & 29 & & & \\
\hline \multicolumn{6}{|l|}{ TPC } \\
\hline Model & 338.1326 & 14 & 24.15233 & 91.70318 & $<0.0001 * *$ \\
\hline$X_{1}$ & 13.80167 & 1 & 13.80167 & 52.4031 & $<0.0001 * *$ \\
\hline$X_{2}$ & 45.76082 & 1 & 45.76082 & 173.7478 & $<0.0001 * *$ \\
\hline$x_{3}$ & 4.576267 & 1 & 4.576267 & 17.37548 & $0.0008^{*}$ \\
\hline$X_{4}$ & 0.680067 & 1 & 0.680067 & 2.582123 & 0.1289 \\
\hline$x_{1} x_{2}$ & 0.046225 & 1 & 0.046225 & 0.17551 & 0.6812 \\
\hline$x_{1} x_{3}$ & 26.4196 & 1 & 26.4196 & 100.3117 & $<0.0001 * *$ \\
\hline$x_{1} x_{4}$ & 0.469225 & 1 & 0.469225 & 1.781585 & 0.2019 \\
\hline$x_{2} x_{3}$ & 0.0144 & 1 & 0.0144 & 0.054675 & 0.8183 \\
\hline$x_{2} x_{4}$ & 0.087025 & 1 & 0.087025 & 0.330422 & 0.5739 \\
\hline$x_{3} x_{4}$ & 0.1225 & 1 & 0.1225 & 0.465116 & 0.5056 \\
\hline$X_{1}^{2}$ & 226.0248 & 1 & 226.0248 & 858.1863 & $<0.0001 * *$ \\
\hline$X_{2}^{2}$ & 0.001296 & 1 & 0.001296 & 0.004922 & 0.9450 \\
\hline$X_{3}^{2}$ & 3.666696 & 1 & 3.666696 & 13.92196 & 0.0020 * \\
\hline$X_{4}^{2}$ & 0.486096 & 1 & 0.486096 & 1.845644 & 0.1944 \\
\hline Residual & 3.950625 & 15 & 0.263375 & & \\
\hline Lack of fit & 3.525492 & 10 & 0.352549 & 4.146336 & $0.0650^{\mathrm{NS}}$ \\
\hline Pure error & 0.425133 & 5 & 0.085027 & & \\
\hline Cor total & 342.0832 & 29 & & & \\
\hline
\end{tabular}

a: Degrees of freedom.

b: Standard deviation $=1.245 ;$ Mean $=202.14$.

c: Standard deviation $=0.51 ;$ Mean $=40.42$.

**: Significance values of "Prob $>F$ " are less than 0.0001 .

*: Significance values of "Prob>F" are less than 0.05 .

NS: Non significant.

\section{Fitting the models}

Table 2 shows the design matrix generated by Design Expert Software (Version 8.0.6). It is composed of 30 experimental runs arranged in randomised order of experiments to minimise the effects of unexplained variability in the response due to extraneous factors. The Analysis of Variance (ANOVA) was done to examine the statistical significance of the quadratic model. The summary of ANOVA analysing of the experimental results are indicated in Table 3. The $F$-value is indicative of whether the quadratic model is significant and the $P$-value indicates the significance of each coefficient. Table 3 shows the $F$-values for the response surface quadratic model for FRAP and TPC to be 275.01 and 91.70 , respectively, with the $P$-values $<0.0001$ indicating only a $0.01 \%$ chance that the model $F$-values may occur due to noise. In other words this result implies the model to be statistically significant and suitable for use. The $F$-values of "lack of fit" as 3.24 and 4.14 for the responses FRAP and TPC have $P$-values insignificant, 0.1029 and 0.0650 , respectively, indicating the "lack of fit" was insignificant in relation to the "pure error". Values of Prob>F less than 0.0500 indicate the model terms are significant. The "Pred $R$-Squared" for the response FRAP and TPC are 0.9798 and 0.9388 , respectively, which are in reasonable agreement with their respective "Adj R-Squared" values of 0.9925 and 0.9776 . The high "Adeq Precision" ratio of 52.44 and 43.35 for the models of FRAP and TPC, respectively, are indicative of adequate signal and minimal noise and hence suitable for navigating the design space. The low coefficients of the variation (CV \%) of 0.6159 for FRAP and 1.6866 for TPC confer very high reliability and degree of precisions to the models.

\section{Optimisation of the extraction conditions}

The predicted response ( $Y_{1}$, FRAP) was achieved by the following second order polynomial equation:

$$
\begin{aligned}
Y_{1}= & 227.03-3.10 X_{1}-1.89 X_{2}+2.01 X_{3}-1.09 X_{4} \\
& -0.40 X_{1} X_{2}-0.23 X_{1} X_{3}-1.73 X_{1} X_{4}+2.08 X_{2} X_{3} \\
& +0.32 X_{2} X_{4}+0.29 X_{3} X_{4}-10.04 X_{1}^{2}-10.18 X_{2}^{2}- \\
& 4.36 X_{3}^{2}-6.54 X_{4}^{2}
\end{aligned}
$$

When the response was FRAP, it was observed that interaction effects of extraction time and extraction temperature $\left(X_{2}, X_{3}\right)$ along with concentration of extractable solids in solvent and solvent concentration $\left(X_{1}, X_{4}\right)$ played significant roles, while all the four factors individually $\left(X_{1}, X_{2}, X_{3}, X_{4}\right)$ were found to significantly affect the response. Figs. $2 \mathrm{a}$ and $\mathrm{b}$ show $3 \mathrm{D}$ response surfaces with contour plots revealing significant effects of con- 

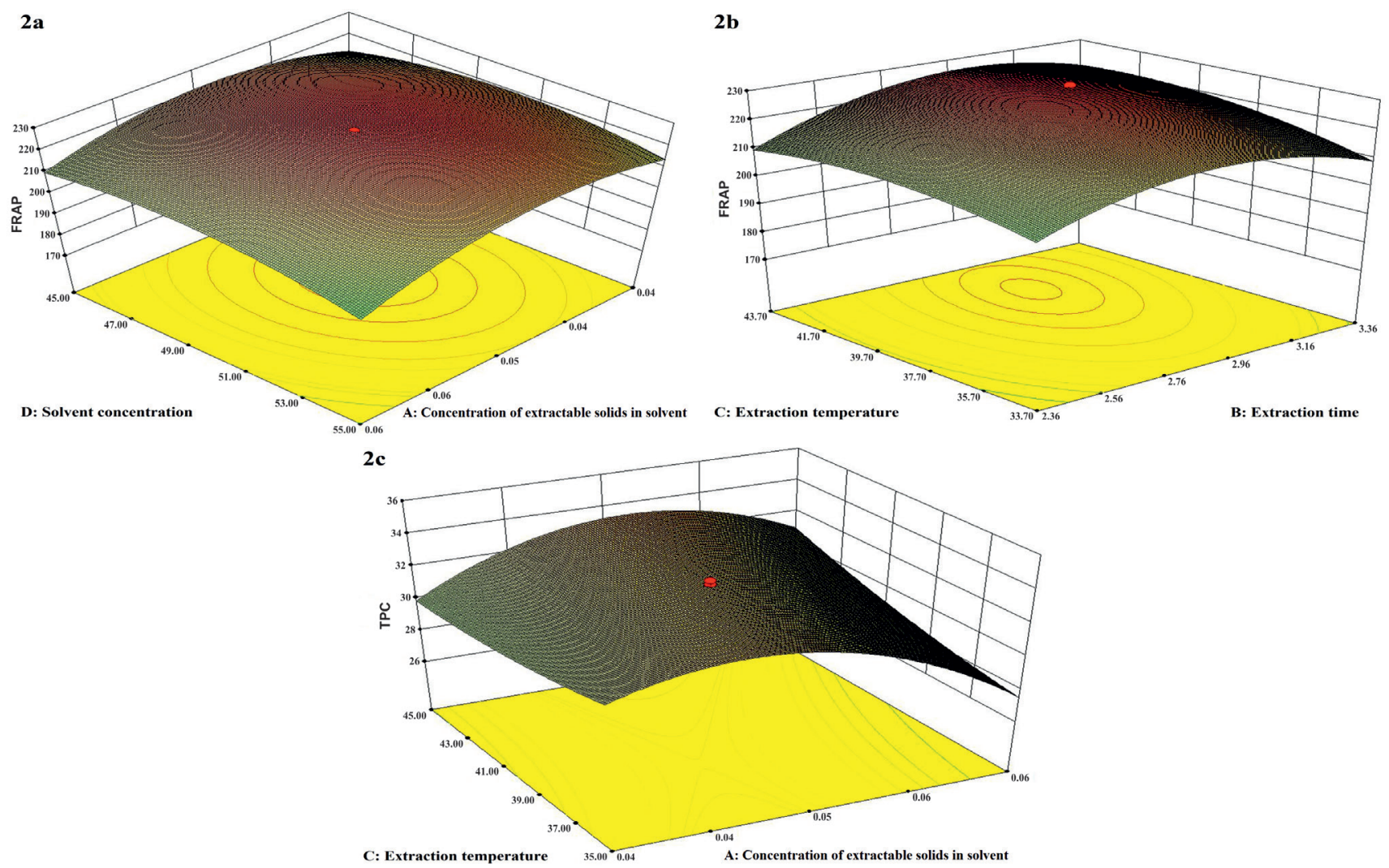

Figure 2. 3D response surface graphs showing the interaction effects of solvent concentration and concentration of extractable solids in solvent for the response of FRAP (2a), extraction temperature and extraction time for the response of FRAP (2b), and extraction temperature and concentration of extractable solids in solvent for the response of TPC (2c)

centration of extractable solids in solvent and solvent concentration $\left(X_{1}, X_{4}\right)$ along with extraction time and extraction temperature $\left(X_{2}, X_{3}\right)$ in maximizing yield of FRAP with the other factors being held at a fixed level (zero level, $X_{1}=0.05 \mathrm{~g} / \mathrm{ml}, X_{4}=50 \%$ and $X_{2}=2.97 \mathrm{~h}, X_{3}=$ $40{ }^{\circ} \mathrm{C}$, respectively). The yield of FRAP value in $T$. indica seed extracts of various experiments (represented in Table 2) ranged from 179.98 to $227.72 \mu \mathrm{mol} \mathrm{Fe(II)/g}$ of dry sample. The highest FRAP content was obtainable at a concentration of extractable solids in solvent of 0.05 $\mathrm{g} / \mathrm{ml}, 50 \%$ ethanol as solvent, extraction temperature of $40{ }^{\circ} \mathrm{C}$ and extraction time of $3 \mathrm{~h}$. The quadratic surface in Fig. 2a describes too low and too high concentration of extractable solids in solvent and solvent concentration $\left(X_{1}, X_{4}\right)$ to have negative impact on antioxidant extraction. Fick's second law states that a final equilibrium between the solute concentrations in the solid matrix and in the extraction medium is achieved after a certain time. This describes the nature of the 3D plot (Fig. 2b) where the initially increasing yield of FRAP drops after a certain time. The fall in FRAP at high temperature may be attributed to the degradation of heat labile antioxidant compounds. Earlier ethanol had been reported to be an efficient solvent for antioxidant extraction (Pompeu et al. 2009) and by varying its concentration antioxidant yield also varied (Kiassos et al. 2009). The current findings of the study are in agreement with the previous reports (Liyana-Parthirana and Shahidi 2005) where $50 \%$ ethanol was found to be optimal concentration for extraction purpose. Concentration of extractable solids in solvent greater than $0.05 \mathrm{~g} / \mathrm{ml}$ showed a fall in FRAP value indicating this value to be the equilibrium point (Zhang et al. 2007) beyond which no rise in extraction was possible. The regression coefficient $\left(R^{2}>0.8\right)$ between predicted and experimental results indicated a good fit.

The predicted response $\left(Y_{2}\right.$, TPC) was achieved by the following second order polynomial equation:

$$
\begin{aligned}
Y_{2}= & 32.54-0.75 X_{1}+1.38 X_{2}+0.43 X_{3}+0.16 X_{4}+ \\
& 0.054 X_{1} X_{2}+1.29 X_{1} X_{3}-0.17 X_{1} X_{4}+0.03 X_{2} X_{3} \\
& +0.09 X_{2} X_{4}+0.09 X_{3} X_{4}-2.87 X_{1}^{2}-0.006 X_{2}^{2}+ \\
& 0.37 X_{3}^{2}-0.13 X_{4}^{2}
\end{aligned}
$$

When the response was TPC, it was observed that interaction effect of concentration of extractable solids in solvent and extraction temperature $\left(X_{1}, X_{3}\right)$ along (Fig. 
2c) with individual independent variables of concentration of extractable solids in solvent $\left(\mathrm{m}: \mathrm{v}, \mathrm{g} / \mathrm{ml} ; X_{1}\right)$, extraction time $\left(\mathrm{h} ; X_{2}\right)$, extraction temperature $\left({ }^{\circ} \mathrm{C} ; X_{3}\right)$ played significant roles. The yield of TPC in T. indica seed extracts of various experiments (represented in Table 2) ranged from 20 to $35.87 \mathrm{mg} \mathrm{GAE} / \mathrm{g}$. The highest TPC content was obtainable at a concentration of extractable solids in solvent $\left(X_{1}\right)$ of $0.05 \mathrm{~g} / \mathrm{ml}, 50 \%$ ethanol as solvent, extraction temperature of $50{ }^{\circ} \mathrm{C}$ and extraction time of $3 \mathrm{~h}$. While concentration of extractable solids in solvent was found optimal at $0.05 \mathrm{~g} / \mathrm{ml}$, increasing extraction temperature showed an increasing trend in TPC yield. Higher temperature might have increased phenolic solubility by increasing the diffusion rate, extraction rate (Ju and Howard 2003) and also breaking the cell wall of plant material resulting in greater solubility. The regression coefficient $\left(\mathrm{R}^{2}>0.8\right)$ indicated a good fit between predicted and experimental results.

\section{Validation of the model}

The optimal extraction parameters were verified for the highest polyphenolic antioxidant content (TPC, FRAP) based on the values obtained using RSM. The optimal condition was established by using maximum desirability for TPC and FRAP. The optimised condition predicted by the model was recorded to be concentration of extractable solids in solvent of $0.049 \mathrm{~g} / \mathrm{ml}$, extraction time for $3.24 \mathrm{~h}$, extraction temperature of $45{ }^{\circ} \mathrm{C}$ and a solvent concentration of $50 \%$ which predicted to yield 222.58 $\mu \mathrm{mol} \mathrm{Fe}(\mathrm{II}) / \mathrm{g}$ FRAP and $33.98 \mathrm{GAE} / \mathrm{g}$ TPC. Experiment was carried out to compare the results of experimental and predicted data. At the optimal conditions $223 \mu \mathrm{mol}$ $\mathrm{Fe}(\mathrm{II}) / \mathrm{g}$ FRAP and 34.15 GAE/gTPC were obtained. The experimentally obtained values fall within a 95\% mean confidence interval of the predicted value for FRAP and TPC. These results confirm the validity and predictability of the model for the extraction of phenolic antioxidant from T. indica seeds.

\section{Conclusion}

The findings of the study suggested aqueous ethanol to be the most suitable solvent for antioxidant extraction from tamarind seed and a strong correlation between TPC and FRAP values led to the conclusion that phenolic compounds were responsible for the overall antioxidant activity of tamarind seed. The response surface methodology was successfully utilised to optimize the phenolic extraction from $T$. indica seeds. The secondorder polynomial model gave a satisfactory description of the experimental data. Under optimized conditions the experimental values agreed with the values predicted by the model. The experimental conditions allow a fast, quantitative and maximum extraction of phenolic antioxidants from $T$. indica seeds.

\section{Acknowledgement}

The financial support by Department of Science and Technology under Ministry of Science and Technology, Government of India in the form of INSPIRE fellowship for doctoral studies (sanction order no. DST/INSPIRE Fellowship/2015/IF 150107) is acknowledged.

\section{References}

Akowuah GA, Ismail, Z, Norhayati I, Sadikun A (2005) The effects of different extraction solvents of varying polarities on polyphenols of Orthosiphon stamineus and evaluation of the free radical-scavenging activity. Food Chem 93(2):311-317.

Anderson MJ, Whitcomb PJ (2016) RSM Simplified: Optimizing Processes Using Response Surface Methods for Design of Experiments, Special Indian ed. Taylor \& Francis Group, New York.

Benzie IFF, Strain JJ (1996) The ferric reducing ability of plasma (FRAP) as a measure of "antioxidant power": The FRAP assay. Anal Biochem 239:70-76.

Cacace JE, Mazza G (2003) Mass transfer process during extraction of phenolic compounds from milled berries. J Food Eng 59(4):379-389.

Clay KL, Murphy RC, Watrins WD (1975) Experimental methanol toxicity in the primate: analysis of metabolic acidosis. Toxicol Appl Pharm 34(1):49-61.

Herodež ŠS, Hadolin M, Škerget M, Knez Ž (2003) Solvent extraction study of antioxidants from Balm (Melissa officinalis L.) leaves. Food Chem 80(2):275-282.

Ju ZY, Howard LR (2003) Effects of solvent and temperature on pressurised liquid extraction of anthocyanins and total phenolics from dried red grape skin. J Agric Food Chem 51:5207-5213.

Kiassos E, Mylonaki S, Makris DP, Kefalas P (2009). Implementation of response surface methodology to optimise extraction of onion (Allium cepa) solid waste phenolics. Innov Food Sci Emerg Technol 10:246-252.

Laroze LE, Díaz-Reinoso B, Moure A, Zúñiga ME, Domínguez H (2010) Extraction of antioxidants from several berries pressing wastes using conventional and supercritical solvents. Eur Food Res Technol 231(5):669-677.

Liyana-Parthirana C, Shahidi F (2005) Optimisation of extraction of phenolic compounds from wheat using response surface methodology. Food Chem 93:47-56.

MacFaul PA, Ingold KU, Lusztyk J (1996) Kinetic solvent 
effects on hydrogen atom abstraction from phenol, aniline, and diphenylamine. The importance of hydrogen bonding on their radical-trapping (antioxidant) activities. J Org Chem 61(4):1316-1321.

Malik CP, Singh MB (1980) Plant Enzymology and Histoenzymology. Kalyani Publishers, New Delhi, India.

McMartin KE, Ambre JJ, Tephly TR (1980) Methanol poisoning in human subjects: role for formic acid accumulation in the metabolic acidosis. Am J Med 68(3):414-418.

Nakchat O, Meksuriyen D, Pongsamart S (2014) Antioxidant and anti lipid peroxidation activities of Tamarindus indica seed coat in human fibroblast cells Indian J Exp Biol 52:125-132.

Pinelo M, Rubilar M, Jerez M, Sineiro J, Núñez MJ (2005) Effect of solvent, temperature, and solvent-to-solid ratio on the total phenolic content and antiradical activity of extracts from different components of grape pomace.J Agri Food Chem 53(6):2111-2117.

Pompeu DR, Silva EM, Rogez H (2009) Optimisation of the solvent extraction of phenolic antioxidants from fruits of Euterpe oleracea using Response Surface Methodology. Biores Technol 100:6076-6082.

Sarkar A, Ghosh U (2016) Classical single factor optimisation of parameters for phenolic antioxidant extraction from tamarind seed (Tamarindus indica). Plant Sci Today 3(3):258-266.

Spigno G, Tramell L, De Faveri DM (2007) Effects of extraction time, temperature and solvent on concentration and antioxidant activity of grape marc phenolics. J Food Eng 81(1):200-208.
Sudjaroen Y, Haubner R, Würtele G, Hull WE, Erben G, Spiegelhalder B, Owen RW (2005) Isolation and structure elucidation of phenolic antioxidants from Tamarind (Tamarindus indica L.) seeds and pericarp. Food Chem Toxicol 43(11):1673-1682.

Treybal RE (1981) Mass-transfer Operations, 4th ed. McGraw-Hill International Editions, Singapore.

Tsuda T, Mizuno K, Ohshima K, Kawakishi S, Osawa T (1995) Supercritical carbon dioxide extraction of antioxidative components from tamarind (Tamarindus indica L.) seed coat. J Agri Food Chem 43(11):2803-2806.

Turkmen N, Sari F, Velioglu YS (2006) Effects of extraction solvents on concentration and antioxidant activity of black and black mate tea polyphenols determined by ferrous tartrate and Folin-Ciocalteu methods. Food Chem 99(4):835-841.

Valgimigli L, Ingold KU, Lusztyk J (1996) Antioxidant activities of vitamin $\mathrm{E}$ analogues in water and a Kamlet-Taft $\beta$-value for water. J Am Chem Soc 118(15):3545-3549.

Yilmaz Y, Toledo RT (2006) Oxygen radical absorbance capacities of grape/wine industry by products and effect of solvent type on extraction of grape seed polyphenols. J Food Comp Anal 19(1):41-48.

Yu J, Ahmedna M, Goktepe I (2005) Effects of processing methods and extraction solvents on concentration and antioxidant activity of peanut skin phenolics. Food Chem 90(1):199-206.

Zhang ZS, Li D, Wang LJ, Ozkan N, Chen XD, Mao ZH, Yang HZ (2007) Optimization of ethanol-water extraction of lignans from flaxseed. Sep Purif Technol 57(1):17-24. 